\title{
Effect of Grapevine Age on the Aroma Compounds in 'Beihong' Wine
}

\author{
Gang Du ${ }^{1,2,3}$, Jicheng Zhan ${ }^{1}$, Jingyuan Li $^{1}$, Yiling You ${ }^{1}$, Yu Zhao ${ }^{1}$, Weidong Huang ${ }^{1,3^{*} \dagger}$ \\ (1) College of Food Science and Nutritional Engineering, China Agricultural University, Beijing 100083, China \\ (2) Tianjin Key Laboratory of Food Biotechnology, College of Biotechnology and Food Science, Tianjin University of \\ Commerce, Tianjin 300134, China \\ (3) Beijing Key Laboratory of Viticulture and Enology, Beijing 100083, China
}

*Contributed equally to this work

Submitted for publication: August 2011

Accepted for publication: September 2011

Key words: Beihong wine, SPME-GC/MS, aroma compounds, aromatic series, grapevine ages

\begin{abstract}
The main aim of this study was to determine the influence of grapevine age $(3,6$ and 12 years) on the aroma compounds in 'Beihong' wine. Aroma compounds in wine were analyzed by solid-phase microextraction gas chromatography-mass spectrometry (SPME-GC/MS). Thirty-three (33) volatile compounds were identified and quantified. The majority of aroma compounds were esters (20) and the concentration of these totaled $90.63-92.82 \%(w / w)$ of the total aroma compounds; particularly, ethyl octanoate and ethyl decanoate. Through the descriptive analysis aroma profile for 'Beihong' wine, the highest aroma contribution was from the fruity and floral series. As the age of the grapevine increased, the concentrations of total volatiles and total odor activity values $(\mathrm{OAVs})$ of the wines significantly increased $(\mathrm{p}<0.001)$. This suggests that grapevine age could affect berry composition, enhance the content of wine aroma compounds and improve wine quality.
\end{abstract}

\section{INTRODUCTION}

The 'Beihong' grape is a late-ripening red wine cultivar derived from 'Muscat Hamurg' $\times$ ' $V$. amurensis'. The 'Beihong' berry matures by the end of September in Beijing. This variety is attractive to Chinese organic wine-making industries. There are several reasons for the interest in 'Beihong': (a) It has a high soluble solid (23.8-27\%) (w/w) and appropriate acid content ( $\mathrm{pH} 3.2-3.4)$; (b) it is highly resistant to cold and can grow in most places in Northern China without needing to be covered in winter when the temperature is usually very low; (c) it has high resistance to disease and can grow in some of the warm humid areas of Southern China; (d) 'Beihong' wine has a balanced taste and delightful odor, in particular a Muscat aroma.

When buying wine, aroma is one of the most important quality attributes to consumers (Lorenzo et al., 2008; Tao et al., 2009). To date, several hundred volatile aroma compounds such as alcohols, esters, organic acids, aldehydes, ketones and terpenes have been identified in wine and their combination forms the character of wine and distinguishes one wine from another. Over 800 volatile compounds have been found in wines, with a wide concentration range varying from hundreds of $\mathrm{mg} / \mathrm{l}$ to the $\mu \mathrm{g} / \mathrm{l}$ or $\mathrm{ng} / \mathrm{l}$ level (Marti et al., 2003).
The aroma profile of a wine is influenced by many factors: grape variety, climatic conditions, soil, region, cultivation techniques, yeast, enological techniques and aging (Jackson and Lombard, 1993; Moret et al., 1994; Dirninger et al., 1998; Fischer et al., 1999; Jones and Davis 2000; Falqué et al., 2001; Gómez-Míguez et al., 2007). However, few studies have investigated the effect of grapevine age on the aroma compounds in wine, especially in 'Beihong' wine. Thus, the objective of this study was to determine the influence of grapevine age (3, 6 and 12 years) on the major volatile compounds in 'Beihong' wine.

\section{MATERIALS AND METHODS \\ Grape sampling}

The grapevines were grown at the Institute of Botany, the Chinese Academy of Sciences, Beijing, China. The soil in the vineyard was sandy (yellow-brown-soil) and the row and vine spacing were $2.5 \times 1.0 \mathrm{~m}$, respectively. Grape samples were harvested at $24^{\circ}$ Brix on the basis of similar size and absence of physical injuries or infections. Sixty (60) grapevines were selected from ten (10) rows and 1 grape sample each from 3, 6 and 12 year-old grapevines, respectively. 


\section{Yeast strains}

Two different strains of Saccharomyces cerevisiae were tested. The commercial strain $S$. cerevisiae $\mathrm{R}_{2}$ (Lallemand, France) was used as reference standard. S. cerevisiae wine yeast strain $\mathrm{BH} 8$ was isolated from the 'Beihong' wine grape variety, cultivated by the Institute of Botany, the Chinese Academy of Sciences, Beijing, China (Li et al., 2010). This strain was identified as $S$. cerevisiae by color and colony topography on WL Nutrient Agar (Pallmann et al., 2001) as well as DNA sequence analysis, conducted in the Institute of Microbiology, Chinese Academy of Sciences, Beijing, China. These commercial yeast strains are widely used in Chinese wine factories with good results.

\section{Fermentation experiments}

After harvesting, the 'Beihong' grapes were immediately destemmed, softly crushed and sulfur dioxide added (sulfited) to a final concentration of $20 \mathrm{mg} / \mathrm{L}$. The musts were clarified by cold-settling for $18 \mathrm{~h}$ at $10^{\circ} \mathrm{C}$ to separate the clear juice from the sediment. Finally, the $\mathrm{pH}$ was adjusted to 3.3 by aseptically adding tartaric acid $(85 \%, \mathrm{w} / \mathrm{v})$. This organic acid was selected because it is normally found in grapes and wines and is very rarely metabolized by ascomycetous yeasts. The 'Beihong' grape must was sterilized with $0.2 \%(\mathrm{v} / \mathrm{v})$ dimethyl dicarbonate for $48 \mathrm{~h}$ at $4{ }^{\circ} \mathrm{C}$ to allow decomposition (Pérez-Torrado et al., 2002).

Fermentations were carried out in 1L flasks with $800 \mathrm{ml}$ medium and fitted with lids that excluded the atmospheric oxygen, but enabled the carbon dioxide to escape and samples to be removed. The initial yeast inoculums were $1 \times 10^{6} \mathrm{cells} /$ $\mathrm{ml}$ from cultures grown overnight in YPD medium $(1 \%, \mathrm{w} / \mathrm{v}$, yeast extract, $2 \%$, w/v, peptone and $2 \%$, w/v, glucose).

Fermentations with two different yeast strains in the grape must of 3, 6 and 12 year-old grapevines, respectively, were derived in triplicate at $15^{\circ} \mathrm{C}$, without shaking. The weight loss of the fermenters was monitored and the fermentation stopped when the $\mathrm{CO}_{2}$ release was less than $0.2 \mathrm{~g} /$ day.

\section{General enological parameters}

The general parameters of the wine were analyzed according to the Office International de la Vigne et du Vin. (1990). The following parameters were analyzed: alcohol percentage, reducing sugar, $\mathrm{pH}$, total acidity, free $\mathrm{SO}_{2}$ and dry extract.

\section{Reagents and standard solutions}

All standard solutions were purchased from Sigma-Aldrich (China sector) and Fluka (Buchs, Switzerland). Sample solutions were prepared using the methods reported by Howard (Howard et al., 2005). The internal standard was 4-Methyl-2-pentanol. For quantification, 5-point calibration curves for each compound were prepared using the method described by Ferreira et al. (2000). This was also used as a reference to determine the concentration range of standard solutions. The regression coefficients of the calibration curves were above $97 \%$ (w/w).

\section{HS-SPME procedure}

Aroma compounds were extracted from the wine samples by HS-SPME and analyzed using gas chromatography/mass spectrometry as described by Zhang et al. (2007). A five milliliter sample of wine and $1 \mathrm{~g} \mathrm{NaCl}$ were placed in a 15 $\mathrm{mL}$ sample vial. The vial was tightly capped with a PTFEsilicon septum and heated at $40^{\circ} \mathrm{C}$ for $30 \mathrm{~min}$ on a heating platform with agitation at $400 \mathrm{rpm}$. The SPME $(50 / 30 \mu \mathrm{m}$ DVB/Carboxen/PDMS, Supelco, Bellefonte, PA, USA), preconditioned according to the manufacturer's instructions, was then inserted into the headspace, where extraction occurred for $30 \mathrm{~min}$ with continued heating and agitation, using a magnetic stirrer. The fiber was subsequently desorbed in the GC injector for $25 \mathrm{~min}$.

\section{GC-MS analysis}

The GC-MS system used was an Agilent 6890 GC equipped with an Agilent 5975 mass spectrometer. The column used was a $60 \mathrm{~m} \times 0.25 \mathrm{~mm}$ HP-INNOWAX capillary with 0.25 $\mu \mathrm{m}$ film thickness ( $\mathrm{J} \& \mathrm{~W}$ Scientific, Folsom, CA, USA). The carrier gas was helium at a flow rate of $1 \mathrm{~mL} / \mathrm{min}$. Samples were injected by placing the SPME fiber at the GC inlet for 25min with the splitless mode. The oven's starting temperature was $50^{\circ} \mathrm{C}$, which was held for $1 \mathrm{~min}$, then raised to $220^{\circ} \mathrm{C}$ at a rate of $3^{\circ} \mathrm{C} / \mathrm{min}$ and held at $220^{\circ} \mathrm{C}$ for $5 \mathrm{~min}$. The mass spectrometry in the electron impact mode (MS/ EI) at $70 \mathrm{eV}$ was recorded in the $\mathrm{m} / \mathrm{z}$ range 20 to $450 \mathrm{U}$. The mass spectrophotometer was operated in the selective ion mode under auto tune conditions and the area of each peak was determined by ChemStation software (Agilent Technologies). The analyses were repeated three times.

\section{Statistical analysis}

All statistical procedures were performed through SPSS version 16.0 statistical package for Windows (SPSS Inc., USA). A one-way analysis of variance (ANOVA) was used to gauge differences between means of volatiles amounts employing Duncan's multiple range tests at a level of $p<0.001$, and the results were presented as mean $\pm \mathrm{SD}$ of triplicate runs.

\section{RESULTS AND DISCUSSION \\ General composition of wine}

After approximately three weeks, all the fermentations were completed (final concentration of sugar $<4 \mathrm{~g} / \mathrm{l}$ ). The general composition of the wine is shown in Table 1. 'Beihong' wine made from grapevines of three different ages and two yeast strains did not show significant differences $(p<0.05)$ in dry extract, total acidity, $\mathrm{pH}$, free $\mathrm{SO}_{2}$, reducing sugar and ethanol concentration.

\section{Aromatic profile analysis}

The volatile compounds isolated from 'Beihong' wine made from grapes taken from grapevines of different ages and using two different yeast strains are listed in Table 2. Odor descriptors and thresholds are also listed in Table 2. In this study, the olfactory perception threshold and odor descriptors of the compounds in wine were taken from information available in the literature (Guth, 1997; López et al., 1999; Ferreira et al., 2000; Culleré et al., 2004; Peinado et al., 2004; Gómez-Míguez et al., 2007; Li et al., 2008; Liberatore et al., 2010; Pino \& Queris, 2011). A total of 33 compounds were identified and quantified in 'Beihong' wine, including alcohols (4), aldehydes (3), terpenes (2), acids (4) and esters 
TABLE 1

General composition of wines

\begin{tabular}{ccccccc}
\hline \multirow{2}{*}{ Composition of wine } & \multicolumn{5}{c}{ Type of wine $^{\mathrm{a}}$} \\
\cline { 2 - 6 } & $3 \mathrm{~B}$ & $3 \mathrm{R}$ & $6 \mathrm{~B}$ & $6 \mathrm{R}$ & $12 \mathrm{~B}$ & $12 \mathrm{R}$ \\
\hline Alcoholicity $(\mathrm{v} / \mathrm{v}, \%)$ & $12.77 \pm 0.17$ & $12.69 \pm 0.17$ & $12.83 \pm 0.27$ & $12.75 \pm 0.19$ & $12.87 \pm 0.21$ & $12.81 \pm 0.15$ \\
Reducing sugar (g/L) & $2.67 \pm 0.07$ & $2.91 \pm 0.08$ & $2.12 \pm 0.05$ & $2.31 \pm 0.06$ & $1.92 \pm 0.04$ & $2.03 \pm 0.05$ \\
Free $\mathrm{SO}_{2}(\mathrm{mg} / \mathrm{L})$ & $5.42 \pm 0.13$ & $5.47 \pm 0.15$ & $5.33 \pm 0.13$ & $5.37 \pm 0.15$ & $5.28 \pm 0.17$ & $5.34 \pm 0.14$ \\
Total acidity $(\mathrm{g} / \mathrm{L})$ & $6.23 \pm 0.14$ & $6.22 \pm 0.15$ & $6.19 \pm 0.13$ & $6.18 \pm 0.16$ & $6.17 \pm 0.24$ & $6.16 \pm 0.21$ \\
pH & $3.42 \pm 0.17$ & $3.43 \pm 0.16$ & $3.41 \pm 0.18$ & $3.42 \pm 0.19$ & $3.44 \pm 0.13$ & $3.45 \pm 0.15$ \\
Dry extract (g/L) & $25.41 \pm 1.24$ & $25.22 \pm 1.32$ & $26.13 \pm 2.07$ & $26.32 \pm 2.15$ & $26.52 \pm 2.37$ & $26.37 \pm 2.21$ \\
\hline
\end{tabular}

Results are the mean values for three independent fermentations

a3B: 3-year-old grapevine, strain BH8; 3R: 3-year-old grapevine, strain R2; 6B: 6-year-old grapevine, strain BH8; 6R: 6-year-old grapevine, strain R2; 12B: 12-year-old grapevine, strain BH8; 12R: 12-year-old grapevine, strain R2.

${ }^{b}$ Measured as $\mathrm{H}_{2} \mathrm{SO}_{4}$

(20). According to the quantitative data, the concentration of total volatiles in the wines ranged from 5470 to $13680 \mu \mathrm{g} / \mathrm{L}$. As the age of the grapevine increased, the concentrations of total volatiles significantly increased $(p<0.001)$. This could be attributed to the effects of grapevine age on berry composition which enhanced the content of wine aroma compounds. The concentration of total aroma compounds from the wines made with strain $\mathrm{BH} 8$ (5960.05, 7605.22 and $13682.93 \mu \mathrm{g} / \mathrm{L}$ for 3,6 and 12 year-old grapevines, respectively) were higher than the wines made with strain $R_{2}$ using the same grapevine (5470.96, 6756.04 and 11022.27 $\mu \mathrm{g} / \mathrm{L}$ for 3, 6 and 12 year-old grapevines, respectively).

Quantitatively, esters were the most abundant group of aromatic components in the wines, followed by alcohols and acids. The subtotal concentration of esters in the wines was in the 4958.38-12638.16 $\mu \mathrm{g} / \mathrm{L}$ range, being $90.63-92.82 \%(\mathrm{w} / \mathrm{w})$ of the total volatile compounds detected. With increased grapevine age, the concentration of esters in the wines significantly increased $(p<0.001)$. The concentration of esters in the wines made with strain BH8 were higher than that in the wines made with strain $\mathrm{R}_{2}$ using the same grapevine. This was attributed to a much higher concentration of ethyl octanoate and ethyl decanoate in the wines made from grapes taken from the 12 year-old grapevine and the absence of ethyl heptanoate, ethyl acetate, propyl octanoate, ethyl tridecanoate and ethyl octadecanoate in the wines made from grapes taken from the 3 or 6 yearold grapevines. Esters are largely responsible for the fresh and fruity aroma of wine and can be produced during the alcoholic fermentation (Rocha et al., 2004). Ethyl esters of fatty acids are formed from ethanolysis of acyl-CoA during fatty acid synthesis or degradation (Lee et al., 2004); these compounds appear mainly during the alcoholic fermentation phase (Gil et al., 2006). On the other hand, the formation of acetate esters is the result of the reaction between acetylcoenzyme A (acetyl-CoA) and alcohols (Lee et al., 2004).

The subtotal concentration of alcohols in the wines was in the $370.95-638.53 \mu \mathrm{g} / \mathrm{L}$ range, being $4.67-6.61 \%(\mathrm{w} / \mathrm{w})$ of the total volatile compounds detected. Alcohols are formed from the degradation of amino acids, carbohydrates and lipids (Antonelli et al., 1999). As the age of the grapevine increased, the concentration of alcohols in the wines significantly increased $(p<0.01)$. The concentration of alcohols in the wines made with strain BH8 was higher than that in the wines made with strain $R_{2}$ using the same grapevine. 1-Decanol was only detected in the wine made from grapes taken from the 3-year-old grapevine with yeast strain BH8. Alcohols were reported to contribute more to the intensity of the odor of the wine than to its quality (Etiévant, 1991).

The concentration of acids detected in the wines was between 91.35 and $393.12 \mu \mathrm{g} / \mathrm{L}$, which was $1.21-2.87 \%$ $(\mathrm{w} / \mathrm{w})$ of the total aroma compounds. The production of fatty acids has been reported to be dependent on the composition of must and fermentation conditions (Schreirer, 1979). There were also significant differences in the type and amount of acids present in the wines $(p<0.001)$ in this study. The concentration of acids was higher in the wines made from grapes taken from the 12 year-old grapevine than in the wines made from grapes taken from the 3 or 6 year-old grapevines. Acetic acid and octanoic acid were only detected in the wines made from grapes taken from the 12 year-old grapevine. Acetic acid is produced during alcoholic and malolactic fermentation. Fatty acids are associated with fatty notes (Rocha et al., 2004).

The concentration of terpenes and aldehydes were much lower than the other aroma compounds. Numerous studies have reported that terpenoid compounds can be used analytically for varietal characterization. Terpene compounds belong to secondary plant constituents, of which the biosynthesis begins with (acetyl Co-A). Microorganisms are also able to synthesize terpene compounds, but the formation of terpenes by Saccharomyces cerevisiae has not yet been observed. Terpenes are an important component of varietal aroma and are not changed by the metabolism of yeast during fermentation (Mateo \& Jiménez, 2000). Benzaldehyde was only detected in the wines made from grapes taken from the 6 year-old grapevine. Decanal was absent in the wines made from grapes taken from the 12 year-old grapevine.

Evaluation of the aromatic profile of the wines was based on the study of "odor activity values" (OAVs), because this aromatic index permits the evaluation of the degree of participation of each compound in the final aroma. In this sense, only compounds with $\mathrm{OAVs}>1$ are considered as 


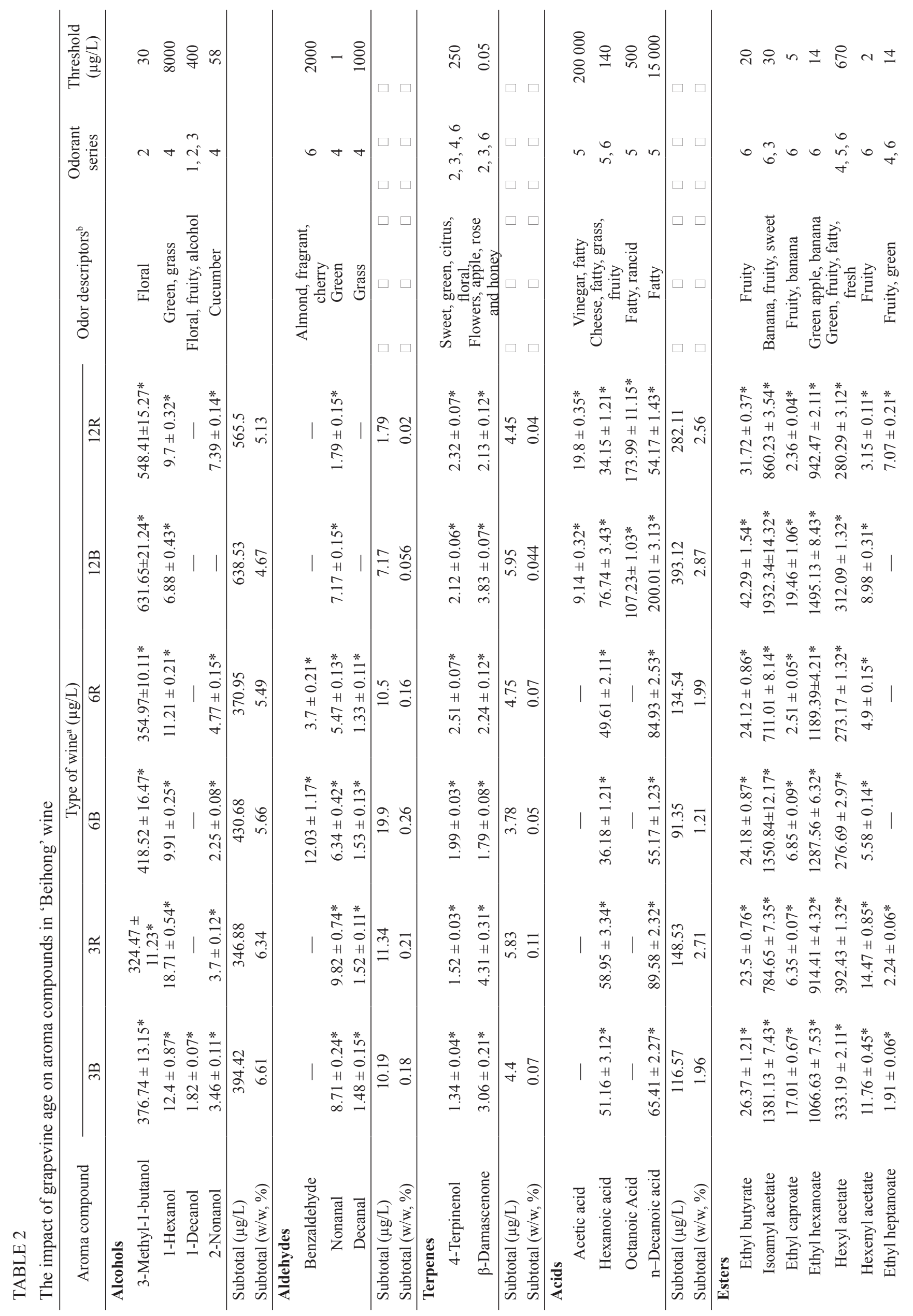




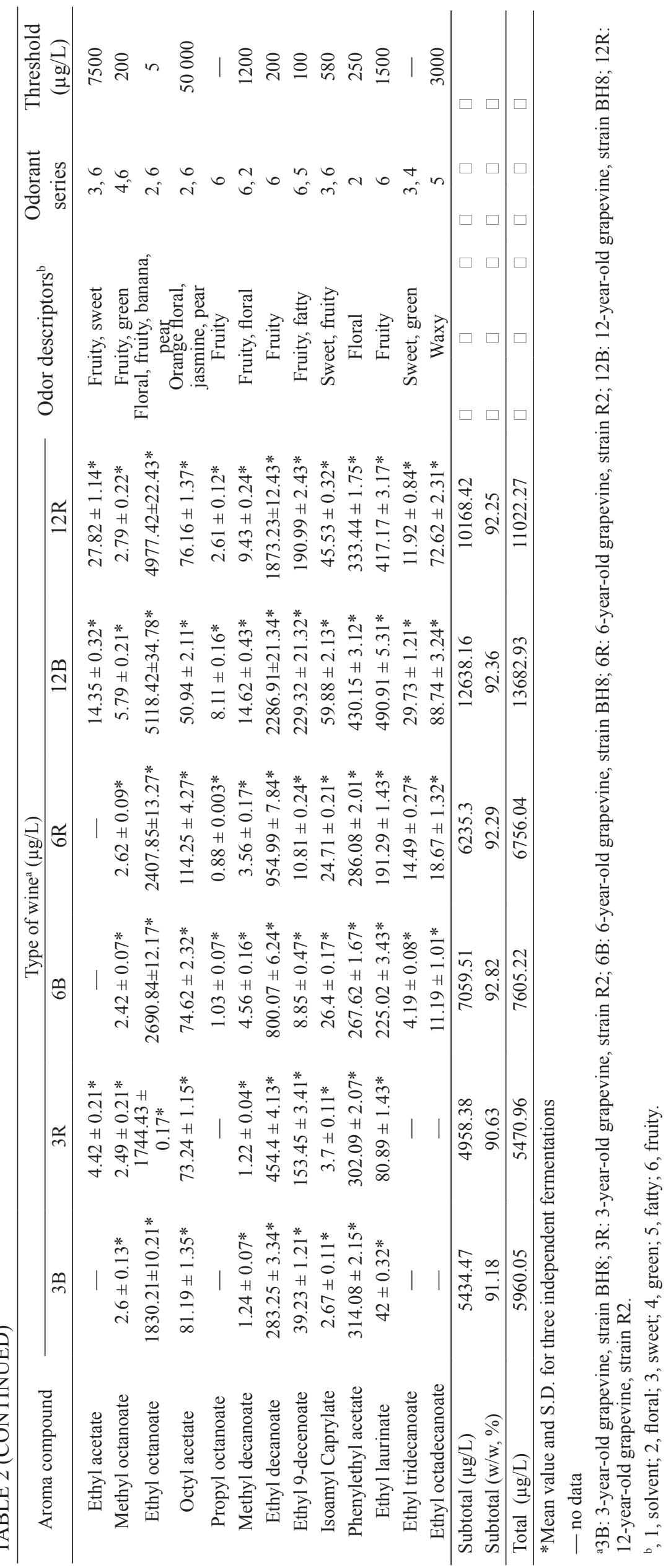


active odorants. OAVs are calculated by using the equation $\mathrm{OAV}=c / t$ (Falqué et al., 2001), where $c$ is the concentration of each compound in the wine and $t$ is the olfactory perception threshold of the compound in wine. Among 33 volatile compounds identified and quantitatively determined in the wines, only twelve (12) compounds were detected at the levels above their odor thresholds $(\mathrm{OAVs}>1)$, which included alcohols (1), aldehydes (1), terpenes (1) and esters (9). Ethyl octanoate had the highest OAV (>900), followed by $(\mathrm{OAVs}>100)$ ethyl hexanoate, then 3-methyl-1-butanol, $\beta$-damascenone, isoamyl acetate and ethyl decanoate reached concentrations above the perception threshold (OAVs $>10)$, followed by nonanal, ethyl butyrate, hexenyl acetate, ethyl caproate, ethyl 9-decenoate and phenylethyl acetate reached concentrations above the perception threshold (OAVs $>1$ ).

Aromatic series can be defined as a group of volatile compounds with similar odor descriptors. On the basis of these odor descriptors, each compound also was assigned to one or several aromatic series: solvent, floral, sweet, green (vegetal or herbaceous), fatty or fruity series, which were chosen on account of their extensive use for describing young white table wines (Peinado et al., 2004). The value of each aromatic series was obtained by adding the OAVs of the compounds that form such a series. Therefore, it is possible to determine the contribution of a specific compound to each series. This procedure makes it possible to relate quantitative information obtained by chemical analysis to sensory perception, providing a single aroma profile based on an young grape plants will horizontally and vertically expand in the soil. This growth period will last about 10-15 years, then stabilize. For the wild hybrid type like "Beihong", the first stage will last longer. Compared with 3 year-old grapevines, 6 and 12 year-old grapevines should have stronger root systems, which will help the grape increase the absorption of individual substances, enhancing the finished wine's aroma and taste. Besides the roots, the number of actinomyces, inorganic phosphorus bacteria and nitrogen fixing bacteria in the soil of 6 and 12 year-old grapevines were more than that of 3-year-old grapevines, based on the results of Luan et al. (2009). It will also enhance the absorption of nutrients. In this study, it was established that the concentrations of total volatiles and total odor activity values (OAVs) of the wines significantly increased $(p<0.001)$ as the age of the grapevine increased. The mechanics between aroma forming and increased nutrition absorption should be elucidated in a future study.

\section{CONCLUSIONS}

This is a first study on the influence of grapevine age (3, 6 and 12 years) on volatile compounds in 'Beihong' wine. This grapevine variety was bred by Institute of botany, The Chinese Academy of Sciences. Thirty-three (33) aromatic compounds were identified and quantified. As the age of the grapevine increased, the concentrations of total volatiles and odor activity values (OAVs) of the wines significantly

TABLE 3

The impact of grapevine age on odor activity values (OAVs) of the odorant series for 'Beihong' wine

\begin{tabular}{cccccccc}
\hline \multirow{2}{*}{ Series } & \multicolumn{7}{c}{ Type of wine a OAVs ${ }^{\text {a }}$} \\
\cline { 2 - 6 } & $3 \mathrm{~B}$ & $3 \mathrm{R}$ & $6 \mathrm{~B}$ & $6 \mathrm{R}$ & $12 \mathrm{~B}$ & $12 \mathrm{R}$ & Significant \\
\hline Solvent & 0 & 0 & 0 & 0 & 0 & 0 & NS \\
Floral & 441.06 & 447.11 & 588.99 & 539.35 & 1123.06 & 1057.70 & $* * *$ \\
Sweet & 107.24 & 112.36 & 80.83 & 68.50 & 141.01 & 71.27 & $* *$ \\
Green & 8.71 & 9.82 & 6.34 & 5.47 & 7.17 & 1.79 & $* *$ \\
Fatty & 0 & 1.53 & 0 & 0 & 11.29 & 1.91 & $* *$ \\
Fruity & 561.48 & 540.04 & 720.33 & 643.46 & 1228.11 & 1148.52 & $* * *$ \\
\hline
\end{tabular}

3B: 3-year-old grapevine, strain BH8; 3R: 3-year-old grapevine, strain R2; 6B: 6-year-old grapevine, strain BH8; 6R: 6-year-old grapevine, strain R2; 12B: 12-year-old grapevine, strain BH8; 12R: 12-year-old grapevine, strain R2.

$\mathrm{NS}$, no significative interaction

${ }^{*} p \leq 0.05, * * p \leq 0.01, * * * p \leq 0.001$

objective. It has recently been used by Peinado et al. (2004). The impact of grapevine age on odor activity values (OAVs) in the odorant series for 'Beihong' wine can be seen in Table 3. The highest aroma contribution was from the fruity and floral series, followed by the sweet, green and fatty series. The solvent series was not detected in the wines and the fatty series was only detected in the wines of $3 \mathrm{R}, 12 \mathrm{~B}$ and $12 \mathrm{R}$. All the odorant series exhibited significant differences in the wines (floral and fruity: $\mathrm{p} \leq 0.001$; sweet, green and fatty: $\mathrm{p} \leq 0.01$ ), except the solvent series. As the age of the grapevine increased, the OAVs of wines significantly increased $(p<0.001)$. The OAVs of wines made with strain BH8 were higher than those of the wines made with strain $\mathrm{R}_{2}$ using the same grapevin3e. Normally after being planted, the roots of increased $(p<0.001)$. These results can be used for wineries to improve the wine quality.

\section{LITERATURE CITED}

Antonelli, A., Castellari, L., Zambonelli, C. \& Carnacini, A., 1999. Yeast influence on volatile composition of wines. J. Agric. Food Chem. 47, 11391144 .

Culleré, L., Escudero, A., Cacho, J. \& Ferreira, V., 2004. Gas chromatography-olfactometry and chemical quantitative study of six premium quality Spanish aged red wines. J. Agric. Food Chem. 52, 1653 1660 .

Dirninger, N., Duc, D., Schneider, C., Dumas, V., Asselin, C. \& Schaeffer, A., 1998. Wine quality and terroirs: Influence of environmental characteristics on the Gewurztraminer flavor profile. Sci. des. Aliment. 18, 193-209. 
Etiévant, P.X., 1991. Wine. In H. Maarse (eds). Volatile compounds in foods and beverages. New York, NY: Marcel Dekker. pp. 483-546.

Falqué, E., Fernández, E. \& Dubourdieu, D., 2001. Differentiation of white wines by their aromatic index. Talanta, 54, 271-281.

Ferreira, V., López, R. \& Cacho, J. F., 2000. Quantitative determination of the odorants of young red wines from different grape varieties. J. Agric. Food Chem. 80, 1659-1667.

Fischer, U., Roth, D. \& Christmann, M., 1999. The impact of geographic origin, vintage and wine estate on sensory properties of Vitis vinifera cv. Riesling wines. Food. Qual. Prefer. 10, 281-288.

Gil, M., Cabellos, J.M., Arroyo,T. \& Prodanov, M., 2006. Characterization of the volatile fraction of young wines from the denomination of origin "Vinos de Madrid" (Spain). Anal. Chim. Acta. 563, 145-53.

Gómez-Míguez, J.M., Gómez-Míguez, M., Isabel, M. \& Heredia, J.F., 2007. Assessment of colour and aroma in white wine vinifications: Effects of grape maturity and soil type. J. Food. Eng. 79, 754-764.

Guth, H., 1997. Quantification and sensory studies of character impact odorants of different white wines varieties. J. Agric. Food Chem. 45, 3027 3032 .

Howard, K.L., Mike, J.H. \& Riesen, R., 2005. Validation of a solid-phase microextraction method for headspace analysis of wine aroma components. Am. J. Enol. Viticult. 56, 37-45.

Jackson, D.I. \& Lombard, P.B., 1993. Environmental and management practices affecting grape composition and wine quality - A review. Am. J. Enol. Vitic. 44, 409-430.

Jones, G.V. \& Davis, R.E., 2000. Climate influences on grapevine phenology, grape composition, and wine production and quality for Bordeaux, France. Am. J. Enol. Vitic. 51, 249-261.

Lee, S.J., Rathbone, D., Asimont, S., Adden, R. \& Ebeler, S.E., 2004 Dynamic changes in ester formation during chardonnay juice fermentations with different yeast inoculation and initial Brix conditions. Am. J. Enol. Vitic. 55, 346-53.

Li, H., Tao, S.Y., Wang, H. \& Zhang, L., 2008. Impact odorants of Chardonnay dry white wine from Changli County. Eur. Food. Res. Technol. 227, 287-292.

Li, H., Wang, H.L., Du, J., Du, G., Zhan, J.C. \& Huang, W.D., 2010 Trehalose protects wine yeast against oxidation under thermal stress. World. J. Microb. Biotechnol. 26, 969-976.

Liberatore, T.M., Pati, S., Nobile, A.D.M. \& Notee, L.E., 2010. Aroma quality improvement of Chardonnay white wine by fermentation and ageing in barrique on lees. Food. Res. Int. 43, 996-1002.

López, R., Ferreira, V., Hernández, P. \& Cacho, J. 1999. Identification of impact odorants of young red wines with Merlot, Cabernet Sauvignon and Grenache grape varieties: a comparative study. J. Agric. Food Chem. 79, $1461-1467$.
Lorenzo, C., Pardo, F., Zalacain, A., Alonso, G.L. \& Salinas, M.R., 2008 Complementary effect of Cabernet Sauvignon on Monastrell wines. J. Food. Compos. Anal. 21, 54-61

Luan, L.Y., Fang, Y.L., Song, S.R., Zhang, Z.W., Cheng, B.S., Qu, Y.P., $\&$ Zhou, Y., 2009. Soil microbe in vineyards with different Tree Ages and different soil depths. J. of NW F Univ. 34-41.

Marti, M. P., Mestres, M., Sala, C., Busto, O. \& Guasch, J., 2003. Solidphase microextraction and gas-chromatography olfactometry analysis of successively diluted samples. A new approach of the aroma extract dilution analysis applied to the characterization of wine aroma. J. Agric. Food Chem. $51,7861-7865$

Mateo, J.J. \& Jiménez, M., 2000. Monoterpenes in grape juice and wine (Review). J. Chromatogr. A. 881, 557-567.

Moret, I., Scarponi, G. \& Cescon, P., 1994. Chemometric characterization and classification of five Venetian white wines. J. Agric. Food Chem. 42, $1143-1153$

Office International de la Vigne et du Vin. (1990). Recuil des methodes internationales d'Analyse des vins et des moûts. Paris

Pallmann, C.L., Brown, J.A., Olineka, T.L., Cocolin, L., Mills, D.A. \& Bisson, L.F., 2001. Use of WL medium to profile native flora fermentations. Am. J. Enol. Vitic. 52, 198-203.

Peinado, R.A., Moreno, J., Bueno, J.E., Moreno, J.A. \& Mauricio, J.C., 2004. Comparative study of aromatic compounds in two young white wines subjected to pre-fermentative cryomaceration. Food. Chem. 84, 585-590.

Pérez-Torrado, R., Gimeno-Alcañiz, J.V. \& Matallana, E., 2002. Wine yeast strains engineered for glycogen overproduction display enhanced viability under glucose deprivation conditions. Appl. Environ. Microbiol. 68, 33393344

Pino, A.J. \& Queris, O., 2011. Analysis of volatile compounds of mango wine. Food. Chem. 125, 1141-1146.

Rocha, S.M., Rodrigues, F., Coutinho, P., Delgadillo, I. \& Coimbra, M.A., 2004. Volatile composition of Baga red wine. Assessment of the identification of the would-be impact odorants. Anal. Chim. Acta. 513, 254-262.

Schreirer P., 1979. Flavor composition of wines-a review. Crit. Rev. Food. Sci. 12, 59-111.

Tao, Y. S., Liu, Y. Q. \& Li, H., 2009. Sensory characters of Cabernet Sauvignon dry red wine from Changli County (China). Food. Chem. 114 $565-569$

Zhang, M.X., Xu, Q.F., Duan, C.Q., Qu, W.Q. \& Wu, Y.W., 2007. Comparative study of aromatic compounds in young red wines from Cabernet Sauvignon, Cabernet Franc, and Cabernet Gernischet Varieties in China. J. Food. Sci. 72, 248-252. 